\title{
Pathotypes of Cochliobolus sativus on Barley in North Dakota
}

\author{
M. Valjavec-Gratian and B. J. Steffenson, Department of Plant Pathology, North Dakota State University, Fargo, \\ 58105
}

\begin{abstract}
Valjavec-Gratian, M., and Steffenson, B. J. 1997. Pathotypes of Cochliobolus sativus on barley in North Dakota. Plant Dis. 81:1275-1278.

Spot blotch, caused by Cochliobolus sativus, has become an important disease on two-rowed barley cultivars in North Dakota. Information on the variability of virulence in C. sativus is essential for the development of spot blotch-resistant barley germ plasm. To establish the number and distribution of $C$. sativus virulence types in North Dakota, 22 isolates from the state were evaluated for their virulence on three differential barley genotypes: ND 5883, Bowman, and ND B112. Eleven additional isolates from Minnesota, South Dakota, Nebraska, Colorado, Japan, and China were included for comparison. Three pathotypes were identified from the thirty-three isolates tested based on the infection responses of the three host genotypes. These pathotypes were designated 0,1 , and 2 according to the coded triplet system of nomenclature. In North Dakota, pathotype 0 (exhibits low virulence on all three differentials) comprised $65 \%$, pathotype 2 (exhibits high virulence on Bowman and low virulence on ND 5883 and ND B112) comprised 25\%, and pathotype 1 (exhibits high virulence on ND 5883 and low virulence on Bowman and ND B112) comprised $10 \%$ of the total number of barley isolates examined. Within North Dakota, pathotype 1 was found in the east-central and northeastern region only, whereas pathotypes 2 and 0 were distributed throughout the state where samples were taken. Isolates with the pathotype 1 virulence pattern were identified in Colorado, Nebraska, Japan, and China. The remaining isolates collected outside North Dakota were pathotype 0. The information obtained from this study will facilitate the deployment of effective resistance to $C$. sativus in barley.
\end{abstract}

Additional keywords: Hordeum vulgare, virulence diversity

The fungus Cochliobolus sativus (Ito \& Kuribayashi) Drechs. ex Dastur (anamorph Bipolaris sorokiniana (Sacc.) Shoemaker) has an extremely wide host range, including barley, wheat, and rye $(10,14)$. On barley (Hordeum vulgare L.), this pathogen causes three diseases: spot blotch, common root rot, and kernel blight or black point (8). Prior to the mid-1960s, spot blotch was especially damaging on barley grown in the upper midwestern region of the United States (8). Yield losses ranging from 16 to $33 \%$ have been reported for susceptible barley lines, depending on the environmental conditions $(9,17)$. The importance of spot blotch has decreased over the past 30 years due to the deployment of highly resistant six-rowed malting barley cultivars in the region $(11,17)$. However, the disease still poses a threat to two-rowed barley cultivars, which generally possess lower levels of resistance to spot blotch (3).

Two-rowed barley cultivars are grown for feed in North and South Dakota, and have increased in production area from

Corresponding author: B. J. Steffenson

E-mail: bsteffen@badlands.nodak.edu

Accepted for publication 28 July 1997.

Publication no. D-1997-0919-01R

(C) 1997 The American Phytopathological Society
13,550 ha in 1985 (1) to 154,350 ha in 1995 (2). Bowman (PI 483237) was the first tworowed barley cultivar bred specifically for the western Dakotas, and was classified as moderately resistant to spot blotch when it was released in 1984 (4). In 1990, Bowman and lines derived from it became severely infected with spot blotch in a breeding nursery in eastern North Dakota (3). Fetch and Steffenson (3) demonstrated that the resistance in Bowman and some of its progeny was effective against the $C$. sativus isolate ND85F, which has been used routinely in disease evaluations of North Dakota barley germ plasm since 1986, and that the occurrence of another virulence type, expressed by isolate ND90Pr, was responsible for the epidemics observed in tworowed barley nurseries since 1990 . In addition, they (3) demonstrated that isolates ND85F and ND90Pr exhibited differential virulence on several two-rowed barley genotypes. Isolate ND90Pr exhibited high virulence on cv. Bowman and its derivatives and low virulence on barley genotypes ND 5883 and ND 12437. In contrast, isolate ND85F was highly virulent on ND 5883 and ND 12437. Both isolates exhibit low virulence on the sixrowed genotype ND B112 (CI 11531), which is the source of the durable spot blotch resistance present in six-rowed malting cultivars $(11,17)$. Line ND B112, therefore, possesses resistance to both virulence types, a characteristic that has not been observed in any of the studied two-rowed genotypes.

Disease control by means of host resistance is possible only if the resistance is effective against all virulence types of the pathogen present in the region of crop cultivation. To effectively breed for spot blotch resistance in two-rowed barley germ plasm, it is essential that information be obtained on the variability of virulence in C. sativus. Thus, the objective of this study was to establish the number and distribution of $C$. sativus virulence types in North Dakota. In addition, this survey was extended by including some isolates of $\mathrm{C}$. $\mathrm{sa}$ tivus from other regions of the United States and from Asia.

\section{MATERIALS AND METHODS}

Fungal isolates. Thirty-six isolates of $C$. sativus were evaluated for their virulence phenotype in this study (Table 1). Most were collected during disease surveys of commercial barley fields or breeding nurseries in North Dakota, but at least one isolate was collected from Minnesota, South Dakota, Nebraska, Colorado, Japan, and China. The primary objective of this study was to characterize the virulence of $C$. sativus in its spot blotch phase; thus, most isolates were obtained from the leaves of barley. R002 (provided by R. W. Stack, North Dakota State University, Fargo) was the only isolate derived from roots (wheat) that was evaluated; it was included to compare the virulence of a root isolate with those derived from the foliage. One isolate from rye also was included in the study. Three isolates of known virulence type were used as controls in the study: ND85F, ND90Pr, and ND93-1. The virulence patterns of isolates ND85F and ND90Pr were described previously by Fetch and Steffenson (3). Isolate ND85F induces low infection responses (IRs) on Bowman and ND B112 and high IRs on ND 5883. This pattern contrasts that of isolate ND90Pr, which induces high IRs on Bowman and low IRs on ND 5883 and ND B112. Isolate ND93-1 exhibits low virulence on barley genotypes ND 5883, Bowman, and ND B112 (16). Isolation, storage, and growing conditions for the conidial cultures were as described in Fetch and Steffenson (3), except that minimal medium (15) was used instead of yeast peptone soluble starch agar.

Barley genotypes. The three barley genotypes ND 5883, Bowman, and ND B112 were used in this study because they previously were found to be useful for differentiating $C$. sativus virulence types 
(3). Bowman was derived from the cross Klages//Fergus/Nordic/3/ND 1156/4/Hector (4). The parent Nordic exhibits moderate resistance to $C$. sativus, presumably due to gene(s) originally derived from ND B112. ND 5883 was selected from a cross between Clipper (PI 349366) and the Canadian experimental line 702-10 (3). Line ND B112 was developed at North Dakota State University, Fargo, during the early 1950 s and originates from the cross CI 7117-77/Kindred (17).

Evaluation of the seedling infection responses. Each of the 36 C. sativus isolates was evaluated for the IRs induced on the barley genotypes ND 5883, Bowman, and ND B112. For this purpose, four to six seeds of each genotype were planted in square pots $(12 \times 12 \mathrm{~cm})$ filled with a potting mix consisting of peat moss $(75 \%)$ and perlite (25\%). Slow-release (14-14-14, N-P-K, $0.1 \mathrm{~g}$ per seedling) and water-soluble (15-0-15, N-P-K, 0.2 g per seedling) fertilizers were applied at planting. All seedlings were grown under growth chamber conditions at 21 to $23^{\circ} \mathrm{C}$ with a 16 -h photoperiod (provided by 115-W cool-white fluorescent bulbs emitting 150 to $350 \mu \mathrm{mol}$ photon $\mathrm{m}^{-2} \mathrm{~s}^{-1}$ ).
Seedlings were inoculated with conidial suspensions $(8,000$ conidia per $\mathrm{ml})$ of individual $C$. sativus isolates at the two-leaf stage (12 to 14 days old). Conidial cultures for inoculum production were obtained by aseptically transferring silica-gel crystals with adsorbed conidia onto minimal medium in plastic petri plates. After 10 days of incubation at $21^{\circ} \mathrm{C}$ with a 12 -h photoperiod (20-W cool-white fluorescent bulbs emitting 260 to $280 \mu \mathrm{mol}$ photon $\mathrm{m}^{-2} \mathrm{~s}^{-1}$ ), the conidia were scraped from the agar surface with a rubber spatula, suspended in doubledistilled water, and filtered through a triple layer of cheesecloth. The concentration of conidia was measured by a hemacytometer and adjusted by adding water. A detergent (polyoxyethylene-20-sorbitan monolaurate) was added to the conidial suspension $(100 \mu \mathrm{l}$ of detergent per liter of suspension) to facilitate the even distribution and adsorption of inoculum onto the leaf surfaces. Inoculum (approximately $0.15 \mathrm{ml}$ per plant) was applied to seedlings with an atomizer (model 15; DeVilbiss Co., Somerset, PA) pressured $(55 \mathrm{kPa})$ by an air pump. After inoculation, plants were incubated in the dark for $16 \mathrm{~h}$ in chambers $\left(21^{\circ} \mathrm{C}\right.$ with relative humidity near $100 \%$ ) misted by ultrasonic humidifiers. Next, the chamber doors were opened to facilitate the slow drying of the plant surfaces. When the plants were dry, they were returned to the growth chamber under the same conditions previously described. The second leaves of seedlings were assessed for their IR 8 to 10 days after inoculation using the 0 to 9 rating scale developed by Fetch and Steffenson (3). With this rating scale, IRs of 0 to 5 are considered indicative of low pathogen virulence and 6 to 9 of high pathogen virulence. All isolates were evaluated for their virulence phenotype in two separate experiments, using a completely randomized design.

Pathotype designation. Pathotypes were designated according to the coded triplet nomenclature system of Limpert and Müller (7). This system uses host differentials ordered in subsets of three. The reaction of each pathogen isolate on a differential host component is first described as a binary value: 1 for virulent and 0 for avirulent (i.e., low virulence). Binary values of each component are further converted to decennary values by the conversion factors $2^{0}$, $2^{1}$, and $2^{2}$ for the first, second, and third host differential component in the subset, respectively. Decennary values are summed

Table 1. Isolates of Cochliobolus sativus from different counties of North Dakota and other regions tested for their virulence pattern on barley genotypes ND 5883, Bowman, and ND B112

\begin{tabular}{|c|c|c|c|c|c|c|}
\hline \multirow[b]{2}{*}{ Isolate } & \multirow[b]{2}{*}{ Year collected } & \multicolumn{2}{|c|}{ Geographic origin } & \multirow[b]{2}{*}{ Host/part } & \multirow[b]{2}{*}{ Host genotype } & \multirow[b]{2}{*}{ Row type } \\
\hline & & State/country & County/location & & & \\
\hline ND85F ${ }^{\mathrm{a}}$ & 1985 & ND & Cass & Barley/leaf & Cv. Larker & 6 \\
\hline ND90Pr ${ }^{\mathrm{a}}$ & 1990 & ND & Cass & Barley/leaf & Line I86-519-1 & 2 \\
\hline ND93-1 ${ }^{\mathrm{a}}$ & 1993 & ND & Walsh & Barley/kernel & Cv. Robust & 6 \\
\hline R002 & 1976 & ND & Walsh & Wheat/root & $\ldots{ }^{b}$ & $\ldots$ \\
\hline ND89-1 & 1989 & ND & Cass & Barley/leaf & $\ldots$ & 6 \\
\hline ND89-8 & 1989 & ND & Emmons & Barley/leaf & $\ldots$ & 2 \\
\hline ND89-25 & 1989 & ND & Rolette & Barley/leaf & $\ldots$ & 6 \\
\hline ND89-33 & 1989 & ND & Mountraill & Barley/leaf & $\ldots$ & 6 \\
\hline ND89-37 & 1989 & ND & Dunn & Barley/leaf & $\ldots$ & 2 \\
\hline ND89-38 & 1989 & ND & Mercer & Barley/leaf & Cv. Azure & 6 \\
\hline ND89-40 & 1989 & ND & Sheridan & Barley/leaf & $\ldots$ & 6 \\
\hline ND89R & 1989 & ND & Cass & Rye/leaf & $\ldots$ & $\ldots$ \\
\hline SD91-7 & 1991 & $\mathrm{SD}$ & Roberts & Barley/leaf & Cv. Robust & 6 \\
\hline MN91-11 & 1991 & $\mathrm{MN}$ & Traverse & Barley/leaf & Cv. Robust & 6 \\
\hline ND92-1 & 1992 & ND & Cass & Barley/leaf & Cv. Robust & 6 \\
\hline ND92-2 & 1992 & ND & Cass & Barley/leaf & Cv. Robust & 6 \\
\hline ND92-8 & 1992 & ND & Stutsman & Barley/leaf & Cv. Bowman & 2 \\
\hline ND92-10 & 1992 & ND & Logan & Barley/leaf & Cv. Bowman & 2 \\
\hline ND92-11 & 1992 & ND & Emmons & Barley/leaf & Cv. Bowman & 2 \\
\hline NE92 & 1992 & $\mathrm{NE}$ & Clay & Barley/leaf & $\ldots$ & 6 \\
\hline ND93-11 & 1993 & ND & Cavalier & Barley/kernel & Cv. Robust & 6 \\
\hline ND93-12 & 1993 & ND & Ramsey & Barley/kernel & Cv. Robust & 6 \\
\hline ND95-17 & 1995 & ND & Towner & Barley/leaf & $\ldots$ & 6 \\
\hline ND95-31 & 1995 & ND & Hettinger & Barley/leaf & Cv. Stark & 2 \\
\hline KB001 & 1993 & ND & Cass & Barley/kernel & Cv. Chevron & 6 \\
\hline KB002 & 1993 & ND & Cass & Barley/kernel & Line M64 & 6 \\
\hline KB008 & 1993 & ND & Cass & Barley/kernel & Line B2601 & 6 \\
\hline KB005 & 1993 & ND & Cass & Barley/kernel & Line B2520 & 6 \\
\hline KB361 & 1994 & $\mathrm{CO}$ & Larimer & Barley/kernel & Cv. Steptoe & 6 \\
\hline KB362 & 1994 & $\mathrm{CO}$ & Larimer & Barley/kernel & Cv. Chevron & 6 \\
\hline KB363 & 1994 & $\mathrm{CO}$ & Larimer & Barley/kernel & Line B2601 & 6 \\
\hline KB364 & 1994 & $\mathrm{CO}$ & Larimer & Barley/kernel & Cv. Harrington & 6 \\
\hline JPN95-1 & 1995 & Japan & Shikoku & Barley/leaf & $\ldots$ & 2 \\
\hline JPN95-2 & 1995 & Japan & Shikoku & Barley/leaf & $\ldots$ & 2 \\
\hline CHN95-1 & 1995 & China & Hongshan & Barley/leaf & $\ldots$ & 2 \\
\hline CHN95-2 & 1995 & China & Hongshan & Barley/leaf & $\ldots$ & 2 \\
\hline
\end{tabular}

\footnotetext{
${ }^{a}$ Control isolates previously characterized for virulence patterns on barley $(3,16)$
}

${ }^{\mathrm{b}}$ Information not available or not applicable. 
to derive a single number for each subset. The three differential genotypes used in this study were ordered as follows: ND 5883, Bowman, and ND B112. Because only three host differentials were used, a single-digit number was sufficient for the pathotype code of $C$. sativus isolates. The reaction of each isolate on a differential host component was described as 1 for high virulence (IRs 6 to 9) and 0 for low virulence (IRs 0 to 5). For example, isolate ND85F exhibits high virulence on ND $5883\left(1 \times 2^{0}=1\right)$ and low virulence on Bowman $\left(0 \times 2^{1}=0\right)$ and ND B112 $\left(0 \times 2^{2}\right.$ $=0$ ). Thus, the resulting code number for this pathotype is 1 .

\section{RESULTS}

The IRs induced by the 36 isolates of $C$. sativus on the three barley genotypes were clear and easy to score. Just one or two consecutive (rarely three) IRs were observed on individual plants within each fungal isolate-host genotype combination. The range of IRs observed in each of these combinations was the same in both experiments. The one or two most common IRs observed on the differential hosts to the $C$. sativus isolates over the two experiments are presented in Table 2. Virulence patterns observed for isolates ND85F and ND90Pr agreed with those described by Fetch and Steffenson (3). The low virulence of isolate ND93-1 on the three barley genotypes (16) also was confirmed. Based on their virulence patterns, isolates ND85F, ND90Pr, and ND93-1 were designated pathotypes 1,2 , and 0 , respectively. The other 33 isolates exhibited either low virulence on all three differential host genotypes, or one of two possible low/high virulence patterns on ND 5883 and Bowman, and low virulence on ND B112 as was found for isolates ND85F and ND90Pr. The isolates, therefore, were differentiated into pathotype 0,1 , or 2 . No other pathotypes were identified.

All three pathotypes were found in North Dakota: 13 (65\%) of the state's barley isolates (from either leaves or kernels) were pathotype $0 ; 5(25 \%)$ were pathotype 2 ; and $2(10 \%)$ were pathotype 1 . Within North Dakota, pathotype 1 was found only in Cass and Towner counties, whereas pathotypes 0 and 2 were distributed throughout the state where samples were

Table 2. The one or two most common infection responses observed on barley genotypes ND 5883, Bowman, and ND B112 infected with 36 isolates of Cochliobolus sativus

\begin{tabular}{|c|c|c|c|c|}
\hline \multirow[b]{2}{*}{ Isolate } & \multicolumn{3}{|c|}{ Infection response $^{\mathbf{a}}$} & \multirow[b]{2}{*}{ Pathotype } \\
\hline & ND5883 & Bowman & NDB112 & \\
\hline ND85F & $8-9$ & $2-1$ & $2-1$ & 1 \\
\hline ND90Pr & $2-3$ & $8-9$ & $2-1$ & 2 \\
\hline ND93-1 & $2-3$ & $1-2$ & $1-2$ & 0 \\
\hline R002 & 3 & 2 & $2-3$ & 0 \\
\hline ND89-1 & $2-3$ & $2-3$ & $2-3$ & 0 \\
\hline ND89-8 & 1 & 1 & 1 & 0 \\
\hline ND89-25 & 2 & $2-3$ & $2-3$ & 0 \\
\hline ND89-33 & 3 & 3 & $2-3$ & 0 \\
\hline ND89-37 & 3 & $2-3$ & $2-3$ & 0 \\
\hline ND89-38 & 2 & 2 & 2 & 0 \\
\hline ND89-40 & 1 & 2 & 1 & 0 \\
\hline ND89R & 3 & $2-3$ & $2-3$ & 0 \\
\hline SD91-7 & $4-3$ & $3-4$ & $3-4$ & 0 \\
\hline MN91-11 & 3 & $3-2$ & $3-2$ & 0 \\
\hline ND92-1 & 3 & 2 & $3-2$ & 0 \\
\hline ND92-2 & 2 & 2 & 2 & 0 \\
\hline ND92-8 & 3 & $9-8$ & $3-2$ & 2 \\
\hline ND92-10 & 3 & $8-9$ & $3-2$ & 2 \\
\hline ND92-11 & 4 & $7-8$ & $3-4$ & 2 \\
\hline NE92 & 8 & $2-3$ & $2-3$ & 1 \\
\hline ND93-11 & 2 & 2 & 2 & 0 \\
\hline ND93-12 & 2 & 8 & $2-3$ & 2 \\
\hline ND95-17 & $8-9$ & $2-3$ & $2-3$ & 1 \\
\hline ND95-31 & 2 & 8 & $2-3$ & 2 \\
\hline KB001 & 2 & $1-2$ & $1-2$ & 0 \\
\hline KB002 & $7-8$ & 1 & 1 & 1 \\
\hline KB008 & 2 & $1-2$ & $1-2$ & 0 \\
\hline КВ005 & $1-2$ & $1-2$ & $1-2$ & 0 \\
\hline KB361 & $4-5$ & $2-3$ & $2-3$ & 0 \\
\hline KB362 & $4-5$ & 2 & 2 & 0 \\
\hline KB363 & $2-3$ & $2-3$ & $2-3$ & 0 \\
\hline KB364 & $5-6$ & $2-3$ & $2-3$ & 1 \\
\hline JPN95-1 & $7-8$ & 2 & $2-1$ & 1 \\
\hline JPN95-2 & 2 & $2-1$ & $2-1$ & 0 \\
\hline CHN95-1 & $2-3$ & 2 & $2-1$ & 0 \\
\hline CHN95-2 & 8 & $2-3$ & $2-3$ & 1 \\
\hline
\end{tabular}

a Observed on 8 to 12 seedlings over two experiments. Infection responses were based on the 0 to 9 scale of Fetch and Steffenson (3).

${ }^{\mathrm{b}}$ Pathotypes were designated using the coded triplet nomenclature system of Limpert and Müller (7). taken (Fig. 1). The isolates from wheat (root) and rye were both pathotype 0 (Table 2). In addition to North Dakota, isolates with the pathotype 1 virulence pattern were identified in Colorado, $\mathrm{Ne}$ braska, Japan, and China. The rest (seven) of the isolates collected outside North Dakota were pathotype 0 . Pathotypes 0,1 , and 2 of $C$. sativus were isolated from both barley leaves and kernels in North Dakota. All three pathotypes also were isolated from both row types of barley, although pathotype 0 was isolated more frequently from six-rowed barleys.

\section{DISCUSSION}

Three pathotypes of $C$. sativus were identified from 36 isolates based on the IRs elicited on barley genotypes ND 5883, Bowman, and ND B112. These differential hosts were effective for characterizing $C$. sativus virulence because they all gave clear high and low IRs to the pathogen isolates studied (Table 2). This differential set may be useful for determining $C$. sativus pathotypes on a routine basis in regions where spot blotch of barley is a concern. Further refinement of the differential set could be made by developing near-isogenic lines, each differing for a single resistance gene to $C$. sativus. Resistance to pathotypes 2 and 1 in barley genotypes ND 5883 and Morex (a cultivar derived from ND B112), respectively, is governed by a single gene at the seedling stage $(11,16)$. Therefore, it should be easy to develop a set of nearisogenic lines for spot blotch resistance in a common genetic background.

Pathotype 2 was found only among isolates from North Dakota and appears to be more prevalent and widely distributed in the state than pathotype 1 (Fig. 1). It was found in the southeastern (Cass County), south-central (Emmons County), southwestern (Hettinger County), and northeastern (Ramsey County) regions of the state. In the southwestern region of North Dakota, cv. Bowman (susceptible to pathotype 2) is grown in more than $55 \%$ of the area planted to barley. Therefore, pathotype 2 should be considered a serious threat to the production of this feed barley cultivar. Part of the breeding effort in the North Dakota tworowed barley improvement program is aimed at developing low-protein malting barley cultivars for the export market. With success in this endeavor, the production of two-rowed barley cultivars may shift toward the eastern region of the state, where the environmental conditions for spot blotch epidemics are often highly favorable. Thus, it is essential that two-rowed cultivars developed for eastern North Dakota be bred with resistance that is effective against all of the $C$. sativus pathotypes present in the region.

The spot blotch resistance of midwestern six-rowed malting cultivars has remained effective for more than 30 years and is considered durable $(11,17)$. Only one report of 


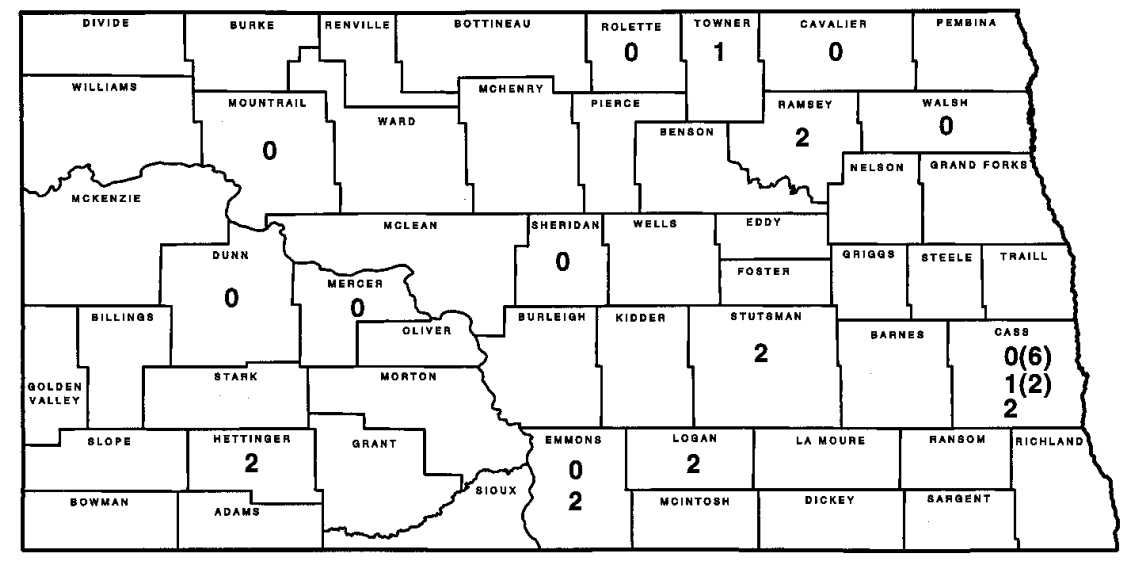

Fig. 1. Distribution of Cochliobolus sativus pathotypes identified from 23 barley isolates collected in North Dakota. The control isolates of ND85F (pathotype 1) and ND90Pr (pathotype 2) from Cass County and ND93-1 (pathotype 0) from Walsh County are included on the map. Numbers in parentheses denote the number of isolates of the pathotype (if more than one) collected from the particular county.

a $C$. sativus isolate with virulence on ND B112 has been made from North Dakota (5). Although this finding has not been confirmed, it raises serious concerns regarding the future longevity of the ND B112 resistance. Nevertheless, further efforts should be made to incorporate resistance from ND B112 into two-rowed germ plasm. At the same time, $C$. sativus isolates from barley and perhaps other hosts should be monitored in order to detect pathotypes that could potentially threaten the ND B112 source of spot blotch resistance.

All three pathotypes of $C$. sativus were isolated from the leaves of six-rowed cultivars with the ND B112 resistance. This suggests that each pathotype of the fungus is capable of infecting and growing on the foliage of resistant barley cultivars in the field. Keeling and Banttari (6) demonstrated that the net blotch pathogen, Pyrenophora teres, could sporulate from small necrotic lesions on resistant barley lines. A similar situation may occur with $C$. sativus on barley.

It is difficult to make any generalizations regarding the tissue specificity of the C. sativus pathotypes, because all three virulence types were isolated from barley leaves as well as kernels, and only one root isolate was included in the study. Spot blotch-infected leaves are probably the primary source of inoculum for the kernel blight phase of the disease; therefore, it is not surprising that similar virulence types were identified from these two tissues. A comprehensive study should be made to determine whether $C$. sativus isolates are specialized to the leaves, roots, or kernels of barley genotypes.

Although only 36 isolates were examined using three differential hosts in this study, C. sativus does not appear as variable as two other common foliar pathogens of barley, Rhynchosporium secalis (the leaf scald pathogen) and $P$. teres. In Manitoba and Saskatchewan, Tekauz (13) identified 28 pathotypes from 51 isolates of $R$. secalis using 10 differential host lines. $R$. secalis is extremely variable with regard to virulence, even though it has no known sexual stage. The sexual stage of $C$. sativus is rare in nature (14), if it exists at all (8). In contrast, the sexual stage of $P$. teres occurs in some regions of Canada. In a recent virulence survey of $P$. teres $\mathrm{f}$. teres in Canada, Tekauz (12) identified 45 pathotypes from 182 isolates using nine differential host lines. Studies on the virulence diversity of fungal pathogens are important. The characterization of pathotypes and their distribution is valuable for programs concerned with breeding for disease resistance. Moreover, this information can provide the foundation for more basic studies on the genetics of host-parasite interactions.
LITERATURE CITED

1. Agricultural Statistics Service. 1986. North Dakota Agricultural Statistics. USDA Agric. Stat. 55. North Dakota State University, Fargo.

2. Agricultural Statistics Service. 1996. North Dakota Agricultural Statistics. USDA Agric. Stat 65. North Dakota State University, Fargo.

3. Fetch, T. G., Jr., and Steffenson, B. J. 1994 Identification of Cochliobolus sativus isolates expressing differential virulence on two-row barley genotypes from North Dakota. Can. J. Plant Pathol. 16:202-206.

4. Franckowiak, J. D., Foster, A. E., Pederson, V. D., and Pyler, R. E. 1985. Registration of 'Bowman' barley. Crop Sci. 25:883.

5. Hosford, R. M., Jr., Solangi, G. R. M., and Kiesling, R. L. 1975. Inheritance in Cochliobolus sativus. Phytopathology 65:699-703.

6. Keeling, B. L., and Banttari, E. E. 1975. Factors associated with the resistance of barley to Helminthosporium teres. Phytopathology 65 : 464-467.

7. Limpert, E., and Müller, K. 1994. Designation of pathotypes of plant pathogens. J. Phytopathol. 140:346-358

8. Mathre, D. E., ed. 1982. Compendium of Barley Diseases. The American Phytopathological Society, St. Paul, MN.

9. Nutter, F. W., Jr., Pederson, V. D., and Foster, A. E. 1985. Effect of inoculations with Cochliobolus sativus at specific growth stages on grain yield and quality of malting barley. Crop Sci. 25:933-938.

10. Sivanesan, A. 1987. Graminicolous species of Bipolaris, Curvularia, Drechslera, Exserohilum and their teleomorphs. Mycological Papers 158. CAB International Mycological Institute, Surrey, England.

11. Steffenson, B. J., Hayes, P. M., and Kleinhofs, A. 1996. Genetics of seedling and adult plant resistance to net blotch (Pyrenophora teres $\mathrm{f}$ teres) and spot blotch (Cochliobolus sativus) in barley. Theor. Appl. Genet. 92:552-558.

12. Tekauz, A. 1990. Characterization and distribution of pathogenic variation in Pyrenophora teres $f$. teres and $P$. teres $\mathrm{f}$. maculata from western Canada. Can. J. Plant Pathol. 12. 141-148.

13. Tekauz, A. 1991. Pathogenic variation in Rhynchosporium secalis on barley in Canada. Can. J. Plant Pathol. 13:298-304.

14. Tinline, R. D. 1988. Cochliobolus sativus, pathogen of wide host range. Pages 113-122 in: Advances in Plant Pathology. Vol. 6. D. S Ingram and P. H. Williams, eds. Academic Press, London.

15. Tinline, R. D., Stauffer, J. F., and Dickson, J. G. 1960. Cochliobolus sativus. III. Effect of ultraviolet light. Can. J. Bot. 38:275-282.

16. Valjavec-Gratian, M. 1996. Genetics of resistance and virulence in the Hordeum vulgare: Cochliobolus sativus pathosystem. Ph.D. dissertation. North Dakota State University, Fargo.

17. Wilcoxson, R. D., Rasmusson, D. C., and Miles, M. R. 1990. Development of barley resistant to spot blotch and genetics of resistance. Plant Dis. 74:207-210. 